\title{
Branding in the Non-profit Context: The Case of Surf Life Saving Australia
}

\author{
Gillian Sullivan Mort, Jay Weerawardena \& Brett Williamson OAM
}

\begin{abstract}
Whilst brand management as a specific sub-field of marketing management is well developed in business research, it is still an emerging area in non-profit organisations. Non-profit organisations are faced with distinct brand challenges, which include issues related to multiple stakeholders in managing the brand and the need to negotiate partnering and sponsorship arrangements. Newly established non-profit organisations can begin their organisational development with strong branding strategies, however many established non-profit organisations have a strong brand heritage, which requires special preservation, renewal and extension strategies. This paper uses a case study methodology to examine the branding issues in Surf Life Saving Australia, a volunteer community beach safety organisation that holds a unique position in the Australian community and cultural psyche, which nevertheless must continually renew and extend its brand heritage in order to achieve its evolving organisational objectives. While the organisation is unique, the paper identifies issues in stakeholder brand management and brand preservation, renewal and extension with wider theoretical and practical implications for non-profit organisations and contemporary perspectives on branding.
\end{abstract}

Keywords: Non-profit branding; Stakeholders; Non-profit brand personality; Non-profit brand heritage; Brand renewal and extension

\section{Introduction}

There is growing consensus (Hankinson 2001; Venable, Rose, Bush and Gilbert 2005; Weerawardena and Sullivan Mort 2006) that non-profit organisations (NPOs) face challenging operational environments. These are characterised by increasing needs in their target communities, rising number of NPOs, growing competition for donors and grants often as a result of 'reinventing government' initiatives which has also given rise to increased numbers of for-profits creating competitive markets in fields traditionally serviced exclusively by NPOs. Given these trends it has been noted that marketing strategy has emerged as a primary tool in the non-profit sector (Venable et al 2005). However, while some promising introductory work has been undertaken (Ritchie, Swami \& Weinberg, 1999; Ewing \& Napoli, 2004), non-profit branding strategy and management has received relatively little attention in the scholarly literature until very recently (Becker-Olsen and Hill, 2006) with the field still being in an early stage of theoretical development. Specifically, we know very little about how NPOs use branding to compete effectively in increasingly volatile and contested markets.

The overall research issue addressed in this paper concerns how brand theory developed in a for-profit business context be applied by non-profit organisations for competitive advantage. To achieve this the paper proceeds as follows. First we provide a conceptual development of branding issues relevant to the nonprofit sector using forprofit frameworks. We then identify three research questions for investigation in the specific context of Surf Life Saving Australia (S.L.S.A.), using a single case study approach. Next we discuss the research method, identify findings and in closing present conclusions and implications.

\section{Conceptual Development of Branding Issues for the Non-profit Sector}

\subsection{Brand concepts and the non-profit brand}

$A$ brand provides the primary point of differentiation 
between competitors and as such they are increasingly acknowledged as critical to a non-profit organization's success in both cross sector and intra-sector competition. The for-profit branding literature is increasingly welldocumented with seminal articles discussing, but not limited to, the basis of brand equity (Keller 1993; Wood 2000), brand personality (Aaker 1997), techniques for building strong brands (Aaker 1996; Macrae and Uncles, 1997) and undertaking successful brand extensions (Keller and Aaker 1992). Branding in the non-profit sector is at a relatively early stage of development (Hankinson 2001) but attention to the issue of branding is growing.

The American Marketing Association (1960) definition of a brand as: a name, term, sign, symbol or design, or a combination of them, intended to identify the goods or services of one seller or group of sellers and to differentiate them from those of competitors has endured to the present day. The strength of this definition lies not only in its identification of some of what have become known as the brand elements that can be used together to facilitate the formation of strong favourable and unique brand associations but also on its focus on the fundamental purpose of branding and differentiation (Kapferer 2001; Wood 2000). Conceptualizations of branding have begun to highlight the intangibles such as personality, non-functional added values and symbolic benefit (Aaker 1996; Keller, Heckler and Houston 1998). Branding in modern marketing practice was initially applied to physical goods and is now increasingly applied in service contexts and lately into the non-profit field. A number of branding concepts and issues identified as particularly relevant to the non-profit sector will now be discussed in detail.

\subsection{Non-profit Organisations and Brand Personality}

Increasingly the strategic importance of brand personality is receiving attention in the for-profit literature, as the focus of development of branding theory shifts from the tangibles such as name, slogan and logo, to the intangible or symbolic aspects such as personality. Brand personality, the set of human characteristics associated with the brand (Aaker 1997), is a focus of interest because of the possibility of a wellestablished brand personality resulting in stronger emotional ties and greater trust and loyalty (Johnson, Soutar and Sweeney 2000), which could also positively impact on competitive advantage.

Aaker (1997) identified five dimensions of brand personality: sincerity, excitement, competence, sophistication and ruggedness. Stride (2006) highlighted the particular importance of values in the context of brand construction in the non-profit field, arguing that the unique aspect of values and the brand for NPOs lies not in the fact that values are involved but that specific values are non-negotiable for NPOs. Further, it was pointed out that the easiest way for a consumer to know if a brand's values reflect their own is via brand personality. Brand personality must be considered in non-profit brand research following Venable et al's (2005) paper on brand personality for NPOs. It identifies four dimensions of brand personality in this context: integrity, ruggedness, sophistication and nurturance. It was anticipated (Venable et al, 2005) that non-profit organizations, armed with insights from brand personality research, could enhance their image and better harness the power of branding. As the characteristics and benefits of becoming involved with a non-profit organisation are largely intangible, a well managed brand and brand personality can facilitate stakeholders' understanding and support (Sargeant 1999). A number of areas for future attention were identified which includes identifying the salience of specific brand personality dimensions to contributions, the effect of culture on non-profit brand dimensions and the need to examine how non-profit brand personality forms and shifts over time. The effect of time on nonprofit brand personality and the link to history or heritage of a non-profit brand seems to hold particular promise.

\subsection{Non-profit Organisations and Brand Heritage}

While branding has received little direct attention in NPOs until recently (Hankinson 2001; Venable et al 2005; Stride 2006) it is acknowledged that the non-profit sector has strong brands, many of which are even global brands such as Greenpeace, Red Cross, Medecins Sans Frontieres and World Wildlife Fund. These brands have most often grown organically over the history of the organisation, rather than strategically, around the efforts of the organisation to develop and meet its identified social mission. NPOs may often be in the position of recognising that their brand comprises a valuable corporate asset without really understanding the details of the asset or how it has developed. As discussed earlier one important aspect of NPOs is that values are strongly implicated in non-profit brands (Stride 2006). We also argue that for non-profit organizations with some longevity their brand has a history of associated 
meaning, a richness in its relationships with many of its stakeholders, and often an embeddedness in particular cultural and historical contexts resulting in a brand heritage and perceptions of the brand being welldeveloped. Simms and Trott (2006) have highlighted the importance of brand history in how stakeholders may have come to associate things with a brand.

Though no agreed definition of brand heritage appears to exist, brand heritage revolves around a brand's history and familiarity, and must thus be related to a brand with some longevity. Heritage is that which is or which may be inherited (Australian Pocket Oxford Dictionary) or passed down from another generation, and is often valued for its links to the past and perhaps for its mere survival. Schultz (2001) has emphasized the importance of brand heritage for internal stakeholders, particularly employees. In mergers and acquisitions he questioned whether 'zapping' the heritage of an acquired brand was a good idea. We identify that many NPOs have brands with a strong heritage, and in some senses are inheritors and custodians of a brand, rather than more simply managers of a strategically constructed and positioned brand. Recently Rekom, Jacobs and Verlegh (2006) have argued that brand managers in the for-profit sector face a particular problem in adapting their brand to changing consumer taste; not losing the essence of the brand. A method for the identification of the essence of brand personality appears to offer a promising area with application in non-profit branding.

\subsection{Non-profit Organisations, Stakeholders and Brand Perceptions}

Stakeholders, 'groups or individuals with whom the organisation interacts or has interdependencies' (Carroll 1993), are important to all organizations. Freeman (1984) defined stakeholders as 'any group or individual who can affect or is affected by the achievement of the organization's objectives' clearly linking stakeholders to organizational strategy. Stakeholders in NPOs include donors and potential donors, granting bodies, government agencies, recipients of benefits or services/clients of the non-profit organization, paid employees, volunteers, businesses who may officially sponsor or otherwise partner with the non-profit and the wider community. One of the major aspects distinguishing for-profits and NPOs can be argued to be the organization's relationships with its stakeholders (Lewis, Hamel and Richardson 2001). It is thus very important to monitor and understand the brand perception held by each group of stakeholders of the NPO's brand. As such, it considerably extends the tasks of brand management of NPOs, compared to those of for-profits which primarily focus on the customers' perceptions of their brand.

Volunteers form a particular stakeholder group unique to NPOs and thus deserve particular attention in relation to branding. Volunteering is undertaken by choice and without obligation, without remuneration, in a more or less organised context and [primarily] for the benefit of others (Cnaan, Handy and Wadsworth 1996). Many different forms of volunteering have been canvassed (Lyons, Wijkstrom and Clary 1998) with volunteering in the delivery of public services being a central aspect in the UK, North America and Western Europe and volunteering as collective action to meet shared needs and address common problems, termed the 'civil society paradigm' of voluntary action, being identified as more common in the rest of the world, including Australia. Recent work (Merrilees, Getz and O'Brien 2005) has modified Freeman's (1984) well-known model of stakeholder management and shows potential to make brand management and communication with non-profit stakeholders (Lewis et al 2001) more effective.

\subsection{Non-profit Organisations and Corporate Branding}

Recently the issue of corporate branding, as distinct from product branding, has received attention in the for-profit literature (Hatch and Schultz 2003) with branding at the corporate level being identified as an interplay of vision, culture and (projected and perceived) image. This issue has received little treatment in the non-profit literature but a number of factors indicate that this is an issue of significance in this domain. NPOs are primarily service organisations and as identified by Berry (2000) in a service context the corporation (organization) and 'not the product is the primary brand'. It follows that the development of a strong non-profit brand must necessarily occur at the organizational level and has potential to provide a distinct competitive advantage. In particular the interplay of vision and culture identified in the for-profit domain are of particular importance for NPOs. Vision maps to the issue of the achievement of the social mission in the non-profit context with achievement of the social mission the reason for being for NPOs and the measure of their success, and culture in non-profit organizations is built around the social mission as core (Weerawardena and Sullivan Mort 2006). 
In NPOs the management of the projected and perceived image involved in corporate branding must be negotiated both externally with multiple stakeholders and internally with the employees and the volunteers. Overall, though there is a substantial literature on branding in the forprofit domain and some emerging work in the non-profit area, we observe that there is little that provides a coherent framework or systematic approach to capture how branding strategies are pursued in NPOs. We argue that the substantive issues that must be addressed include: approaches to brand management; recognition and legitimisation of tangible brand elements; identification of intangible brand values and communication to stakeholders; and recognition of branding at the corporate/organisational level and development of the brand at that level for competitive advantage.

\subsection{Research Questions}

The overall research issue guiding this research is: how brand theory developed in a for-profit business context be applied by non-profit organisations for competitive advantage. Case research affords the opportunity to engage in theory building in an area where little prior research exists (Benbasat, Goldstein and Mead, 1987) as is the situation with non-profit branding. We undertake this research by examining the case of S.L.S.A., a nonprofit organisation dedicated to beach safety and rescue with a strong history and brand heritage. S.L.S.A. can be described as an iconic Australian brand, akin to Vegemite food spread, Holden cars and Akubra hats. Given the centrality of the beach to the Australian culture and national identity, it is an organisation with a rich and distinct set of brand associations that has also needed to develop strategies to respond to environmental challenges to maintain its competitive advantage and achieve its social mission. Following the conceptual development presented above, we identify the following research questions for investigation:

1. How can non-profit brand perceptions be measured and managed? What are the dimensions of the S.L.S.A. brand personality?

2. How are brand elements managed and how is the corporate brand managed?

3. How can non-profit brands respond to changing organizational needs and new stakeholders? What specific branding issues are relevant for sponsorship, product licensing and fund raising activities?

\section{Research Method}

Consistent with the focus of this research, an in-depth case research approach was followed (Yin, 1994). We use a single case study of the instrumental type (Stake 2000). Eisenhardt (1989) and Yin (1994) emphasise the importance of having case study research process grounded in the theoretical literature. Thus collection of data was guided by the literature and research questions outlined above, and a case study protocol was used to guide the data collection process in order to enhance the reliability of the research (Yin, 1994). We have selected S.L.S.A. as an appropriate case to investigate the research questions for a number of reasons. It is a large non-profit organisation operating at the national level with a long history and substantial involvement with the whole community. The size and sustained existence of the organisation reflects its ability to engage in exchanges and deploy resources in the achievement of its goals of beach safety. In particular, the organisation is relatively resource rich with an established governance structure and professional managers.

Following Stake's (2000) recommendations for the study of the particular case we include a description of the following; the nature of the case, physical setting, other contexts (economic, legal, social) and the informant through whom the case can be known.

S.L.S.A. is the leading water safety and rescue authority in Australia. It aims to provide a safe beach and aquatic environment throughout Australia. S.L.S.A. is comprised of a national body with governing bodies in each state of Australia, including the Northern Territory. "The vast majority of Australia's population lives in cities and towns, on or near, the coast. The beach is - and always has been - a place that millions of Australians escape to, where they can relax and play" (Australian Government, 2006). S.L.S.A.'s major activities are (a) surf life saving and water safety activities; (b) research, education and training; and (c) surf sports competitions and social activities.

In 2007 S.L.S.A. celebrates the 100 th year of saving lives on Australian beaches signifying its heritage as one of the most iconic images in Australia. The S.L.S.A. was founded in 1906 at Bondi Beach, Sydney. 'Surf bathing' was initially seen as immoral and was illegal. Men and women could only 'bathe' in the early morning and late evening, and never at the same time. In September 1902 at Manly beach William Gocher openly defied the law. From then on the sport of 'surf bathing' quickly grew and 
as the sport became more popular, the dangers of the surf became apparent. "Over the subsequent decades the S.L.S.A. has become an essential part of the Australian culture and its attachment to the 'sun and sand'. Surfing and the beach do not discriminate. They bring together a diverse range of people. Unlike other places around the world that have privately owned beaches, in Australia the beach is a public place" (Australian Government, 2006).

The physical setting in which the case is carried out is in S.L.S.A. Queensland branch - Surf Life Saving Queensland (S.L.S.Q.), a particular state in Australia. This state has the longest inhabited coastline in Australia with the largest and most-developed network of lifesaving clubs. As such, it is argued that it constitutes an excellent physical context in which to undertake the study. Follow-up interviews were undertaken when the state manager of S.L.S.Q. was appointed as CEO of the national organisation allowing the physical setting to be extended to the national organisation.

In research on the economic and social contribution of the S.L.S.A. (S.L.S.A. Annual Report 2004-2005) it was found that (a) surf life saving services around Australia are valued at more than $\$ 1.6$ billion each year; (b) if S.L.S.A. was not on duty in our beaches 485 people would drown each year and 313 people would be permanently incapacitated as a result of accidents in the surf. In terms of competition, S.L.S.A. enjoys a unique advantage of being the only organisation that provides beach safety and other beach-related social activities. In fund-raising, S.L.S.A. primarily operates in three areas, namely, (a) Surf Life Saving Foundation fund-raising activities (individual focus) (b) strategic partnerships (organisational focus) and (c) government funding (received from government department and agencies).

We address the issue of the key informant because of its importance in the case study. We identify our key informant as a long-time state manager for the organisation who has now taken on the role of Chief Executive Officer at the national level and who speaks directly to the reader as a co-author of the paper. This provides certain advantages in the case analysis, including access to both physical records and organizational memory of key events and issues. It also allows the views of the "actor(s)" (Zonabend 1992) to be directly incorporated. A number of processes were undertaken to ensure data integrity of informant data including the two most common approaches of redundancy of data gathering and procedural challenges to explanation, as part of the analysis of the case study.
As a matter of style, (Stake 2000) we have chosen to identify the organization; primarily because there is only one national beach safety organisation in Australia with a strong brand heritage so it would not in practice be possible to de-identify/anonymise the organisation under study.

In-depth interviews were conducted with the key informant when he was state manager and the key decision-maker for Surf Life Saving Queensland (S.L.S.Q.) with follow-up interviews once he became CEO of S.L.S.A., the national surf life saving body for Australia. CEOs and senior managers are often chosen on merit, as they possess the most comprehensive knowledge of the characteristics of the organization, its strategy and performance (Snow and Hrebiniak 1980; Miller and Toulouse 1986). The main objective of the interviews was to gain an in-depth understanding of how the organization managed its brand and the role of branding in achieving the evolving organizational objectives. The focus questions in the research instrument were open-ended. Prompts were used to expand discussion and to further elicit the views and opinions of the participant (Creswell, 2003). Probes were developed to explore key issues in-depth as they emerged in the interview context. The interviews were taped and later transcribed verbatim and subjected to coding and further analyses as discussed below. Relevant documents, exhibits and archival data about the organization were collected at the time of interviews and also from public records. These included minutes of meetings; original data from the consultants' study of the mid-1990s; the annual report (Surf Life Saving Australia, 2004-2005); the organisational strategy paper Frontline First 2006; the association history "Between the Flags" (Jaggard, 2006); S.L.S.A. Market Research Report (2000); other archival documents of the organisation (Surf Life Saving Australia, 2006); S.L.S.A. Heroes Campaign, 2000; and the National Museum of Australia exhibition. These data were collected to provide triangulation of reference material for thematic analysis and for post-research inquiry (Creswell, 2003).

We made systematic, detailed comparisons across all case data, employing matrices (Miles and Huberman, 1994). The matrix technique promotes pattern matching and the effective categorization of data (Miles and Huberman 1994). Following Eisenhardt (1989), we then tie emergent findings to the extant literature, thereby enhancing internal validity, generalizability and theoretical level. An initial report was written and sent to 
the key informant for review and comments. These comments were incorporated in the final version of the paper, with the informant then assuming a direct authorial voice.

Validity of research is an important issues in qualitative research and indeed validity in terms of credibility and authenticity is often identified as a strength of qualitative research. Three primary strategies (Creswell, 2003) for addressing soundness and validity were implemented in this study. As noted above relevant documents and archival data about the organisation were collected at the time of the open-ended interview and observations made at this time were recorded. These were analysed as described above to provide triangulation of thematic analysis. Member checking (Yin 1994) was implemented by providing a transcript of interview to the key informant, allowing for input. Rich, thick descriptions are used to convey the findings of the research, improving shared experience and judgment of the readers.

\section{Findings}

1. How can non-profit brand perceptions be measured and managed? What are the dimensions of the S.L.S.A. brand personality?

We find that a formal brand audit was undertaken at the national level about S.L.S.A. by the state organisation, S.L.S.Q., in the mid-90s for a strategic purpose, to better understand their brand asset and its dimensions so to formulate better branding strategies with the aim of ensuring financial sustainability and the overall ability of the organisation to sustain its mission. Market research was also undertaken continuing over some years and was formalised in a report S.L.S.A. Market Research Report, 2000. We find that this is consistent with recommended practice in the for-profit sector (Maddox 2006) of undertaking a brand audit to support their strategic decision making. Recently for example, it was reported that the C.E.O. of Nortel - the large multinational telecommunications company - made a brand audit the first part of a strategic decision making about the company's brand (Maddox, 2006). Undertaking a brand audit is identified here as a significant move towards recognising the asset of the brand possessed by S.L.S.A. - a "coming of age" for the organisation in formalising its brand management and a necessary step in enabling the organisation to capitalise on their brand asset.

"We commissioned a company called Company X" to do a report "into what people thought about the brand Surf
Life Saving.......We had started to get serious about our financial sustainability, let alone sustainability for other reasons, but in terms of resources we were living day to day relying on government funds and a handful of sponsors. We had no revenue from donors. Well, we were 90 years old ,... and we did not have a donor program."

We identify that non-profit brand perceptions of S.L.S.A. were measured using methods directly sourced from for-profit business practice. Our analysis of the report indicates the use of focus groups, in-depth interviews and a telephone survey using a mix of qualitative and quantitative research. We highlight that they identified the need to measure the brand perceptions of all stakeholders, not merely of one set of primary stakeholders, the customer.

In choosing the market research firm they involved a partner with experience with for-profit business practices, but also substantial experience in applying market research to political marketing which necessarily draws on expertise in understanding stakeholders, specifically relevant in this non-profit context. A content analysis of the Table of Contents of the audit report shows that a large number of issues customarily analysed in for-profits have been addressed with the same rigor and comprehensiveness. The audit's attention to the perceptions of multiple stakeholders is evident.

The Surf Life Saving Australia brand personality was found to be highly positively regarded by both the corporate sector and the general community stakeholders. It is notable that the corporate perceptions of the brand are more focussed on functional aspects of the brand and the organization, namely safety, Australian, healthy, community focussed and wholesome. Overall, the general community identified the key values of the S.L.S.A. brand as trustworthy, honesty, honourable, friendly, efficient, responsive, dedicated and reliable. On a seven point scale, they rated the brand at 6.5-6.6 on all values, higher than most other organizations (S.L.S.A. Market Research Report, 2000). The general community tended to see the brand in more emotional terms and to identify human characteristics of the brand. While these do not fully reflect the four dimensions subsequently identified by Venable et al (2005) of integrity, ruggedness, sophistication and nurturance there is strong support for the integrity and virtuousness of the Surf Life Saving brand and in addition a strong element of nurturance (dedication) and approachability in the friendliness of the brand. 
Overall, the findings suggest that brand techniques from the for-profit sector can be effectively adopted by NPOs when guided by a manager with a strong brand orientation (Hankinson 2001). The findings also suggest the strategic role of the manager in identifying and innovating by incorporating methods from the business sector capable of use in the non-profit environment adding value to the organization, consistent with a strong socially entrepreneurial orientation (Weerawardena and Sullivan Mort, 2006). It is notable that the S.L.S.A. brand was perceived to have a very distinct and a very positive brand personality by both the corporate and the general public stakeholders. No significant negative attributes were found to be associated with the S.L.S.A. brand which the research firm undertaking the audit commented was a highly unusual finding. It is also noted that no further market research has been undertaken to formally test the brand personality or to monitor any changes that may have occurred over time.

2. How are brand elements managed and how is the corporate brand managed?

The name adopted for use as a formal brand was Surf Life Saving Australia - the same name as the national organisation. This is an inherently meaningful brand name and served to reaffirm the national identity of the organisation to all internal and external stakeholders. Being inherently meaningful, the brand name conforms to the identified branding best practice in naming brands (Kotler 2000). This type of brand name is also associated with higher recall of advertised benefit claims than nonsuggestive brand names (Keller, Heckler and Houston 1998), an obvious competitive advantage. Surf Life Saving Australia's current logo of the human head/face in profile wearing the distinctive life saver's cap in the life savers colour's of red and yellow on a blue background with text identifying the organisation was specifically designed as a result of the brand audit to better identify the brand. This use of consistent visual identity was recommended for NPOs by Bosch, Jong and Elving (2006).

At the same time the tag line / slogan "The life of the beach" was also developed and 'it underpins everything we do'. The prime communication message of the organisation concerning beach safety "Swim between the flags" was found to have a $99 \%$ recognition rate in the brand audit. The red and yellow colours were strongly and consistently associated with both the Surf Life Saving brand and the swim-safe beach flags. All of these suggest that the Surf Life Saving organisation pays consistent attention to the tangible elements of the brand.

With regard to the intangible elements such as the values of the non-profit organization, the vision and mission, organizational culture as well as projected and perceived image that comprise the corporate brand, there is strong evidence of strategic insight and management. The S.L.S.A. website (S.L.S.A., 2006) though accessible by the public is used as a key mechanism for communication to internal stakeholders by the national body S.L.S.A. It identifies five core values for the organisation of tradition (part of Australia's heritage); community (community based institution promoting unity and understanding amongst family and friends); safety (proactive and innovative) and professionalism (conducts business and operations in an efficient and responsible manner) and openness (an open and accessible organization) as guiding values for the internal operation of the organisation. These values are not as simple as the perceived values of the organisation held by corporate stakeholders or the general community reported after market research (S.L.S.A. Market Research Report, 2000). They are planned to be consistent with the external stakeholders' perceptions but to be more specific and detailed to provide greater guidance for strategic and day-to-day management of the organisation. The vision is for "zero preventable deaths and injuries", (Frontline First 2006) and the mission is "to provide excellent beach safety and lifesaving services, water safety advocacy, education and sport" (Frontline First 2006). The core of the organisation is "basically we are a self-help organization" (S.L.S.A., 2006). The culture is aimed at "maintaining and developing supportive relationships with internal stakeholders" (S.L.S.A., 2006).

The brand plays a central role and animates the organization:

"I suppose we try to reinforce the brand in how we live and breath each day across whatever we're doing across the organization"

Careful attention is given to articulating vision, mission and organizational culture using methods and approaches similar to for-profit organizations. There is however a strong emphasis on 'grassroots' members and communication with small, local clubs as well as in managing an organisation with a complex structure, a set of goals and a set of relationships with external parties. Members and office bearers of the organisation are highly valued. 


\begin{abstract}
"Our members are very important to us and we wouldn't annoy them by for example asking them for donations of money. They pay their membership subscription"
\end{abstract}

The tangible brand elements have been refined and the intangibles are monitored and safeguarded, the brand and its values are used internally as an important cultural guide. We identify that there may be some tension inherent in managing, interpreting the corporate brand (Hatch and Schultz, 2003) and its relationship to vision and values which guide the organisation and the simpler set of brand values as perceived by external stakeholders. Overall, brand management is strongly developed in regards to tangibles and intangibles.

3. How can non-profit brands respond to changing organizational needs and new stakeholders? What specific branding issues are relevant for sponsorship, product licensing and fund raising activities?

S.L.S.A. is a volunteer organisation centred around what has been termed the civil society paradigm of voluntary action (Lyons et al 1998). The volunteers take collective action to meet shared needs and address common problems - primarily those of beach safety. The volunteers become members of the association for a subscription paid annually.

"They are volunteers but you don't call them that, they become members of this big family".

The organisation is "uniquely Australian".

“...surf life saving with the funny red and yellow cap and the red and yellow flags started in Australia and it's been exported to a few countries, particularly South Africa, New Zealand, Japan and Great Britain ...... but..ocean or beach lifesaving around the world is professionals, part of the government service ...people look in awe at us...how do we do it....Australia has been federated for just over a hundred years and its something that has been with us during that time...".

A critical time was reached in the 1960s and 1970s with membership declines. This was the era of rising popularity of surf board riding "and to a degree there were almost clashes... People were less inclined to become part of a structured organization. So we have had to realign and restructure and rearrange how we do things as well".

At that time surf life saving was only for men and the organisation was "almost military". A separate organisation was run for children - termed the Nippers.
A significant shift in the member stakeholder group resulted from extending membership, with women and families becoming included as members not only as targets for help.

The 1980s was a time of significant extension to beach sport through the well sponsored and highly visible Iron Man competitions. By the time of the brand audit in the mid-90s, internally it was considered that there was possibly some confusion about what the organisation stood for: serious activities of safety or fun sport activities. The TV campaign "Heroes", undertaken as a result of the brand audit, reinstated core S.L.S.A. values of safety and selflessness and a definite heroic stance, providing a coherent image. In one sense this was repositioning, but it was not about taking on new values for commercial gain as in the traditional for-profit approach. It was a move back towards core, historical, heritage values, consistent with Hankinson's (2001) observation of the role of values in non-profit brands, when there had been a drift of image towards more fun and commercial attributes for surf life-savers.

Heritage values are being reinforced during the centenary of life saving in 2007 , with the production of a history of the organisation (Jaggard, 2006) and an exhibition of surf life saving at the National Museum of Australia in 2006-2007 (National Museum of Australia, 2006). The brand or the visual image of the brand is of an athletic, suntanned (Anglo-Celtic) Australian. The image:

"... is still the muscle bound Aussie bloke but there's also a healthy vibrancy of people of all ages in [the organization] and you'll see that in our promotional campaigns as well".

Recent, beach-related violence in Sydney (Sydney Morning Herald, 2005) has seen the need to explicitly extend the member stakeholder groups again and to renew the brand, while maintaining the heritage elements and values.

"We don't promote well enough the non-white-AngloSaxon component of our membership which is small and needs to be expanded and that's our next stage...you'll see some marketing materials now featuring members that are from non-traditional backgrounds".

S.L.S.A. has increased its monitoring of the competitive environment, maintaining a competitive posture and allowing them to take appropriate response in managing the brand. The case informant identified that: 
"other charities, both national and international were [seen] as becoming very street smart and sophisticated plus there were corporates who were starting to create and exploit their own charities. I mean all very worthy. Ronald McDonald House for example. ......so in direct competition we were the traditional ...community-based worthy organization".

There is an organized, strategic approach to commercial relationships, like licensing and sponsorship and there is a commercial approach to significant events

We appointed an agency to manage our cause-related and trademark licensing program ...there has been sunscreen, there has been clothing ...we've been selective... some products we could not accept because it did not fit with the brand personality"... "Next year (100th anniversary of the organization) the Year of the Surf Life Saver, we've got a logo for the year, a subbrand... we re allowing some of our corporate partners to utilize that as well ..some companies have paid a licence fee to market specific promotional products".

S.L.S.A. has a significant 30-year corporate sponsorship with Westpac Bank, one of Australia's big four banks, and a bank increasingly emphasising its corporate social responsibility (Westpac, 2006). S.L.S.A. also has a four or five year relationship with DHL the international logistics company which, as they entered the Australian market were re-banding and using the same corporate colours, red and yellow, as S.L.S.A did. That was a good strategic partnership with some elements of coincidence in the matching of colours.

The most significant change following the brand audit and market research report has been a much stronger donor/fundraising program. At the time of the audit there was no income from donors, but now $20 \%$ of income is in the form of donations. As a result of the brand audit the organisation learnt that $92 \%$ of people thought that S.L.S.A. was worthy of support but only $2 \%$ of people had supported them. Encouraged by that untapped goodwill, the Surf Life Saving Foundation was repositioned for fundraising:

"That's proving to be very successful ... we will be more and more ... and at some stage hopefully fundraising will be $80 \%$ of our revenue".

The 100th anniversary of S.L.S.A. in 2007 has been treated as a significant event and as an opportunity to revisit and refresh the brand image with the commissioning of a history or the organisation and a year of community events and fundraising.
The S.L.S.A. organisation has evolved significantly in its 100 year history. The core brand values have remained associated with self help for beach safety, health and the Australian way of life. However, there have been significant periods when the brand heritage needed renewal. The case informant used the words 'realign and restructure and rearrange' to describe how the organisation renews itself and its brand. The brand is consciously managed as an organisation asset and the brand and organisation values mediate commercial relationships such as sponsorship, licensing and fund raising.

\section{Conclusions, Implications and Future Research Directions}

S.L.S.A. has successfully used a number of for-profit techniques identifying its brand personality, building and developing brand associations and brand strength. S.L.S.A. has built on these assets for competitive advantage and financial and organizational sustainability allowing it to achieve its social mission. Specifically, S.L.S.A. undertook a brand audit, harmonized and integrated its brand elements and used communication messages strategically to reinforce its brand, as in the 'Heroes' campaign. Repositioning in a commercial sense has not been used, but rather a technique appropriate for NPOs of renewing essential brand values and seeking to extend its stakeholders to encourage new members. It is notable that the core values and heritage of the brand are influential in setting internal direction and cultural management and in guiding external relationships, including commercial options. The brand values are refined and extended to meet organisational needs and emerging strategic directions. Some licence opportunities have been foregone, as they did not fit with brand personality.

For other NPOs, particularly those with a long history, adopting S.L.S.A.'s approach to the brand audit, the clear identification of the brand personality and particularly brand heritage and the strategic approach to brand management both internally and in external relationships provides directions for brand management. S.L.S.A. pays attention not only to the tangibles of branding, naming, colours and logos, but to the intangibles such as brand values. Brand values have a reflexive relationship with the culture of the organisation and guide its external relationships. It is notable that the heritage of being heroic and saving others mediate the commercial relationships. Other NPOs might also benefit from 
S.L.S.A.'s approach to volunteers, where members pay a subscription and become part of a family, which could provide new directions for volunteer relationship management. Constant monitoring of brand values and personality through ongoing market research has not been undertaken by S.L.S.A. which would have been more consistent with for-profit management of a brand. This lack of constant monitoring possibly reflects the non-commercial orientation of the organisation and a response to the need to allocate available resources across a wide range of areas.

Future research on non-profit brands should investigate the conceptualization and measurement of the essence of brand heritage for a non-profit brand, for both existing and potential stakeholders. Understanding heritage brand essence would be a valuable theoretical contribution and in practice would enable challenges, such as the need for S.L.S.A. to increase new ethnic group membership, to be more successfully negotiated.

Future research is also needed to address the issue of sponsorship in-depth. While some research has addressed the benefits of sponsorship fit and its enhancement from the perspective of what a NPO can gain (Becker-Olsen and Hill, 2006), the advantages for enhancing fit and its effect on the sponsoring organisation's brand perceptions has not been addressed. In addition empirical research on how brand management may enhance the overall marketing strategy of the NPO is also needed.

The S.L.S.A. brand has a unique place in the Australian cultural lexicon, not only because of its traditional and continuing association with the beach and the Australian lifestyle, but also because its core brand personality has been well maintained and renewed using strategic brand management appropriate to the non-profit organization.

\section{References}

Aaker, D. 1996. Building equity and advertising: Advertising's role in building strong brands. Erlbaum, Hillside, New Jersey.

Aaker, J. 1997. Dimensions of brand personality. Journal of Marketing Research 34(3), 347-356.

American Marketing Association (AMA). 1960. Marketing definitions: A glossary of marketing terms AMA, Chicago IL.

Australian Government, 2006. Culture and Recreation Portal. Surf Life Saving http://www.cultureandrecreation.gov.au/articles/surflifes aving/Accessed 11 December,

2006.

Australian Pocket Oxford Dictionary. 5th ed 2001. Oxford University Press, Oxford.

Becker-Olsen, K.L. and Hill, R.P. 2006. The impact of sponsor fit on brand equity: The case of non-profit service providers, Journal of Service Research, 9(1), 7383.

Benbasat, I., Goldstein, D.K. and Mead, M. 1987. The case research strategy in studies of information systems, MIS Quarterly, 11(3), 369-386.

Berry, L. 2000. Cultivating service brand equity. Journal of the Academy of Marketing Science 28(1), 128-137.

Bosch, L.M., Jong, M.D.T and Elving, W.J.L. (2006). Managing corporate visual identity, Exploring the difference between manufacturing and service, and profit-making and non-profit organizations, Journal of Business Communication, 43(2), 138-157.

Carroll, A.B. 1993. Business and society: Ethics and stakeholder management. Southwestern Publishing, Cincinnati, $\mathrm{OH}$.

Cnaan, RA., Handy, F. and Wadsworth, M.1996. Defining who is a volunteer. Non-profit and Voluntary Sector Quarterly, 25(3), 364-383.

Creswell, J.W. 2003. Research design: Qualitative, quantitative, and mixed methods approaches. 2nd ed. Thousand Oaks, CA, Sage Publications.

Eisenhardt, K. 1989. Building theories from case study research. Academy of Management Review, 14, 532-550.

Ewing, M. and Napoli, J. 2004. Developing and validating a multidimensional non-profit brand orientation scale, Journal of Business Research, 58(6), 841-853.

Freeman, R. E. 1984. Strategic management: A stakeholder approach. Pitman, Boston, MA.

Frontline First 2006. Strategic Plan 2004-2008. Surf Life Saving Queensland.

Hankinson, P. 2001. Brand orientation in the charity sector: a framework for discussion and research. International Journal of Non-profit and Voluntary Sector Marketing 6(3), 231-242.

Hatch, M.J. and Schultz, M. 2003. Bringing the 
corporation into corporate branding. European Journal of Marketing 37(7/8), 1041-1064.

Jaggard, E (Ed.) 2006. Between the Flags - one hundred summers of Australian surf lifesaving. UNSW Press: Sydney, Australia.

Johnson, L., Soutar, G. and Sweeney, J. 2000. Moderators of the brand image / perceived product quality relationship. Journal of Brand Management, 7(6), 425-433.

Kapferer, J-N. 2001. Re-inventing the brand. Kogan Page, London.

Keller, K.L. 1993. Conceptualizing, measuring, managing customer-based brand equity. Journal of Marketing 57(1), 1-22.

Keller, K. L. and Aaker, D.A.. 1992. The effects of sequential introduction of brand extensions. Journal of Marketing Research 29(1), 35-51.

Keller, K.L., Heckler, S.E. and Houston, M. 1998. The effects of brand name suggestiveness on advertising recall. Journal of Marketing, 62(1), 48-57.

Kotler, P. 2000. Marketing Management. The Millennium Edition. Prentice Hall: NJ.

Lewis, L. K., Hamel, S.A. and Richardson, B.K. 2001. Communicating change to non-profit stakeholders. Management Communication Quarterly, 15(1), 5-41.

Lyons, M., Wijkstrom, P. and Clary, G. 1998. Comparative studies of volunteering: What is being studied? Voluntary Action, 1(1), 45-54.

Macrae, C. and Uncles, M.D. 1997. Rethinking brand management: The role of "brand chartering", Journal of Product and Brand Management, 6(1), 64-84.

Maddox, K. 2006. Nortel CMO begins global brand unit. $\mathrm{B}$ to $\mathrm{B}$ 91(6), 3-4.

Merrilees, B., Getz, D. and O'Brien, D. 2005. Marketing stakeholder analysis: Branding the Brisbane Goodwill Games, European Journal of Marketing, 39(9/10), 10601077.

Miles, M. and Huberman, M. 1994. Qualitative data analysis. Sage, Thousand Oaks, CA.

Miller, D. and Toulouse, J.-M. 1986. Chief executive personality and corporate strategy and structure in small firms. Management Science, 32(11), 1389-1409.

National Museum of Australia 2006. Exhibitions -
Between the Flags: 100 years of surf life saving http://www.nma.gov.au/exhibitions/exhibit_1.html Accessed 11 December, 2006.

Rekom, J.G. Jacobs and Verleigh, P. 2006. Measuring and managing the essence of a brand personality, Marketing Letters, 17, 181-192.

Ritchie, R.J.B., Swami, S. and Weinberg, C.B. 1999. International Journal of Non-profit and Voluntary Sector Marketing, 4(1), 26-42.

Sargeant, A. 1999. Charitable giving: towards a model of donor behaviour, Journal of Marketing Management 15, 215-238.

Schultz, D.E. 2001. Zapping brand heritage, Marketing Management, 10(4), 8-9.

Simms, C. and Trott, P. 2006. The perceptions of the BMW Mini brand: The importance of historical associations and the development of a model, Journal of Product and Brand Management, 15(4), 228-238.

Surf Life Saving Australia (S.L.S.A.) Annual Report 2004-2005

Surf Life Saving Australia (S.L.S.A.) Heroes Campaign. Video. 2000.

Surf Life Saving Australia (S.L.S.A.) Market Research Report, 2000.

Surf Life Saving Australia (S.L.S.A.) www.slsa..com.au Accessed 28 September 2006.

Snow, C. and Hrebniak, L 1980. Strategy, distinctive competence and organizational performance, Administrative Science Quarterly, 25(2), 317-336.

Stake, R.E. 2000. Case studies, 435-454 in Denzin, N. K. and Y. S. Lincoln (Eds). Handbook of Qualitative Research 2nd ed Sage: Thousand Oaks, CA.

Stride, H. 2006. An investigation into the values dimensions of branding: Implications for the charity sector, International Journal of Non-profit and Voluntary Sector Marketing, 11(2), 115-124.

Sydney Morning Herald 2005. Mob violence envelops Cronulla, December 11, 2005 http:/www.smh.com.au/news/national/mob-violenceenvelops-cronulla/2005/12/11/1134235936223.html Accessed December 11, 2006.

Venable, B., Rose, G.M., Bush, V.D. and Gilbert, F.W. 2005. The role of brand personality on charitable giving: 
an assessment and validation, Journal of the Academy of Marketing Science 33(3), 295-312.

Weerawardena J. and Sullivan Mort, G.M. 2006. Investigating social entrepreneurship: A multidimensional model, Journal of World Business 41(1), 21-35.

Westpac 2006. Corporate responsibility: Sustainable value generation http://www.westpac.com.au/internet/ publish.nsf/Content/WICR + Sustainable + value + generati on Accessed December 11, 2006.

Wood, L. 2000. Brands and brand equity: Definition and management, Management Decision 38(9), 662-669.

Yin, R. 1994. Case Study research: Design and methods. 2nd ed. Thousand Oaks CA, Sage Publications.

Zonabend, F. 1992. The monograph in European ethnology, Current Sociology, 40(1), 49-60.

\section{Biographies}

Dr Gillian Sullivan Mort is associate professor of marketing at Griffith Business School, Griffith University, Australia. She researches in nonprofit marketing, social entrepreneurship, international marketing and e-marketing. Her work has been published in such journals as Journal of Advertising Research, Journal of World Business and International Marketing Review.
Dr Jay Weerawardena is senior lecturer in marketing in UQ Business School, University of Queensland, Australia. He researches in international marketing, innovation-based competitive strategy, non-profit marketing and new service development. He has published in such journals as European Journal of Marketing, Journal of Business Research, Journal of World Business and Journal of Strategic Marketing.

Mr Brett Williamson, OAM, is the CEO of Surf Life Saving Australia and has extensive expertise in surf life saving, beach safety, nonprofit administration and government liaison and consultancy. He holds an Australian Sports Medal, Australian Centenary Award, World Life Saving Citation of Merit and is a Fellow of the Australian Institute of Management and a Fellow of the Australian Society of Sports Administrators.

\section{Correspondence Address}

Gillian Sullivan Mort, Griffith Business School, Griffith University, Nathan Campus, Brisbane, Australia. Telephone: +617373 57344. Email: gillian.mort@griffith.edu.au; Jay Weerawardena, UQ Business School, University of Queensland, St Lucia, Brisbane, Australia. Email: j.weeerawardena@business.uq.edu.au; Brett Williamson OAM, Surf Life Saving Australia, Icebergers Building, Bondi Beach, Sydney Australia. Email: williamson@lifesaving.com.au 